\title{
Conexiones inestables, imprevistas y pérdidas: expandiendo la arena política en la cooperación para el desarrollo y comunidades indígenas en el Chaco paraguayo \\ Valentina Bonifacio
}

- Marie-Curie Research Fellow Ca' Foscari University / Parsons - The New School for Design / Veneza, Itália / Nova York, ny, Estados Unidos

vvalentina.bonifacio@unive.it

\section{Rodrigo Villagra Carron}

- Tierraviva a los Pueblos Indigenas del Chaco / Candidato a investigador Programa Nacional de Impulso a Investigadores-CONACYT

villagrarodrigo@hotmail.com

\section{RESUMEN}

Este trabajo es una reflexión sobre la arena política en el contexto paraguayo y más allá de ella. En particular, permite una mirada más cercana al modo como este campo es desplegado y, a la vez, borrado en el espacio de encuentro entre comunidades indígenas e instituciones de desarrollo. Se parte, para ello, de dos casos de estudio. El primero es el de las comunidades maskoy del Alto Paraguay, en donde la ausencia de formas "desarrollistas" de organizaciones indígenas se complementa con una fuerte revalorización de ceremonias colectivas que, aun no siendo consideradas políticas por los no-indígenas, ciertamente lo son si se reformulan desde una distinta perspectiva ontológica. El segundo es el caso de la comunidad sanapaná y enxet de Xakmok Kásek, en el cual se trabaja con una organización no gubernamental que ofrece apoyo jurídico-político a la comunidad para reclamar parte de sus tierras ancestrales ante el Parlamento paraguayo, a través de un proyecto de ley de expropiación que afecta a un ganadero que posee el título de las mismas. Al acercarse el momento de discusión del proyecto de ley en plenario, la comunidad pide a la organización un apoyo adicional para realizar una reunión de chamanes, de modo a estos que actúen sobre los legisladores. El ejemplo muestra, de nuevo, que el campo de la política no se reduce meramente a las acciones de los humanos. Ambos casos, en conjunto, demuestran los fútiles intentos desarrollistas para separar lo "humano" de la "naturaleza" y la dificultad de las organizaciones de apoyo para comprender a cabalidad la política como una cosmopraxis indígena. De este modo, los desafíos puestos por los indígenas a los límites "modernos" de la arena política provocan tensiones y malentendidos, y reclaman un análisis detenido, así como una reconceptualización e imaginación para futuras alianzas y prácticas políticas.
PALABRAS-CLAVE

Arena política, Desarrollo, Pueblos Indígenas del Chaco, Chamanismo, Cosmopraxis. 


\section{INTRODUCCIÓN}

Este artículo es el resultado de una reflexión común y de un compromiso de largo plazo con pueblos indígenas en Paraguay. Ambos autores hemos trabajado - si bien desde diferentes puestos y puntos de vista- en el campo de la cooperación internacional y en cercana relación con lo que ha venido a conocerse como "organizaciones indígenas". Nuestro objetivo es enlazar diferentes elementos, a fin de desafiar el modo como, en el contexto de las organizaciones indígenas, la arena política es actualmente enmarcada en el plano de la cooperación internacional. Esperamos, con eso, abrir nuevos caminos para pensar sobre ella.

Nuestras reflexiones se deben, en gran parte, al análisis de Marisol De La Cadena de la "aparición de seres terrestres en protestas sociales" en el contexto peruano - y en América Latina en general- lo que evidencia "un momento de ruptura en la política moderna" (2010: 336)'. En particular, estamos interesados en qué tipo de forma tal ruptura podría tomar en el caso de la praxis política que emerge entre la cooperación para el desarrollo y las comunidades indígenas en Paraguay.

Primero que todo, pensamos ser necesario especificar qué significa para nosotros, en el contexto del Chaco paraguayo, los "seres terrestres" a los que alude De la Cadena - lo cual está directamente relacionado con un conjunto de prácticas que los propios pueblos indígenas traducen como "chamanismo", y que nosotros encontramos entre los sanapaná, los enxet y otros pueblos emparentados a estos. Los chamanes son nombrados como apyoholhma' o apyohoxma en los idiomas sanapaná y enxet respectivamente. Podría traducirse esta frase substantivada como "el que sabe el mundo" (Kalisch, 2012: 356); si bien ellos también son conocidos como akma[-]pmopvaan (persona con poder), kelaaney' pook (sanador) o apvaanyam' (anciano) (Kalish, 2012: 363-364) en el cercano idioma enlhet; y como mba'e kuaa (el que sabe las cosas) o paje (brujo/encantador) entre los maskoy y angaité de habla guaraní paraguayo.

Los chamanes solían ser generalmente hombres, pero hay en el presente, y hubo en el pasado, algunas mujeres chamanas. Como Villagra indica, ellos Ilegaban a ser tales a través de un largo y continuo proceso de aprendizaje, el cual requería ayunar por varios días, al cabo de los cuales se ingería plantas (y/u otros objetos adicionales) que habían sido dejadas pudrir en agua. A través de ese padecimiento y procedimiento, se hacía posible divisar, en trance o en sueño, al dueño "espiritual" de tales elementos ingeridos. Para los pueblos citados más arriba, el cosmos no está solo habitado por seres humanos, animales y plantas, sino por muchos otros tipos de seres, tales como aquellos del tipo enxet-enlhet, similar a la "gente", y aquellos clasificados simplemente como aksok (cosas). Tampoco el cosmos tiene una sola dimensión, sino que es multidimensional: en sus
1 Todas las citas relativas a obras de De la Cadena son traducciones hechas por los autores de este artículo. 
diferentes niveles, viven diferentes tipos de seres. Los chamanes son los capacitados para viajar a esos otros niveles, con el objeto de encontrar a estos seres. Los chamanes más experimentados supervisan a los aprendices de chamanes, con el objetivo de encontrar a sus espíritus auxiliares. Si la búsqueda es bien sucedida, tales espíritus aparecerán a los chamanes en sus respectivas moradas, en una forma reconocible — sea zoomórfica o antropomórfica-y, desde el primer encuentro, querrán ayudar a sus compañeros humanos a dominar las "cosas" $y$ los "poderes" que ellos mismos manejan. Estas "cosas" pueden ser animales de los bosques y de los cielos, peces y plantas de los ríos y bañados, otros seres de diversa apariencia monstruosa, objetos foráneos manufacturados, como dinero y aviones, y así sucesivamente. Entre otros nombres, los espíritus auxiliares son Ilamados apmovana (sus habilidades) y, como Villagra ha señalado en otro trabajo (2009: 155), así como ya lo había hecho anteriormente Kidd (1999: 41), tales seres son sumamente diversos y han venido cambiado su apariencia y variedad - dentro de la dinámica de la colonización-en un flexible e interminable proceso de innovación. Empero, un chamán puede también referirse a su espíritu auxiliar como su [-]ásenneykha, que literalmente significa "aquellos a los cuales uno le dice que hacer" (Kidd, 1999: 40)². Los maskoy y los angaité traducen este concepto al guaraní paraguayo o al castellano como ita'yra (su hijo), imba'e kuera (sus cosas), o como che socio (mi socio), mi "compañero" o "espíritu".

Es a los espíritus auxiliares y a las "cosas" que ellos manejan y con quienes se relacionan que nos referimos cuando reflexionamos sobre la aparición de "seres terrestres" en el dominio político, a los cuales, a su vez, se refiere De la Cadena en su trabajo. Apoyándose en Latour, ella afirma que "estos objetos son contenciosos debido a que su aparición en política desobedece a la separación entre 'naturaleza' y 'humanidad' en la cual la teoría política que nuestro mundo acata ha sido históricamente fundada" (2010: 342). Adaptando su análisis al contexto del Chaco paraguayo, podríamos decir que la relación entre ciertos seres humanos y ciertos espíritus auxiliares es constitutiva de la condición de persona y lleva a la emergencia de una nueva clase de sujetos políticos.

En una discusión sobre el concepto de persona en la comunidad andina en donde trabaja, De la Cadena analiza el concepto de runakuna que los habitantes utilizan cuando se refieren a ellos mismos. Según la antropóloga, es una equivocación pensar en los runakuna fuera de sus relaciones con algunos seres terrestres no humanos (los tirakuna), pues ambos "llegan a ser a través de las relaciones que los habilitan" (2014: 255). "El ensamblaje que hace ser los runakuna con los tirakuna, los hace posibles de una manera que el ensamblaje que separa los humanos de los no-humanos los haría" (De la Cadena, 2014: 256). Lo que queremos argumentar en este artículo es que el sujeto político que emerge de la relación con los espíritus auxiliares está solo parcialmente conectado con
2 Véase también, sobre el tópico de seres auxiliares: Arenas (1981) y Kidd (1992) 
el sujeto político al que la cooperación internacional suele referirse y conceptualizar. Esta divergencia habilita distintas arenas políticas como un conjunto de prácticas que niegan ciertas relaciones, enfatizando, a su vez, otras.

Para usar la terminología de De la Cadena, los seres terrestres (a los cuales también podríamos llamar seres metafísicos o habitantes del cosmos indígena multidimensional) han hecho su aparición en el espacio público en el contexto de protestas políticas, a través de rezos, cantos y danzas determinadas. En el Chaco paraguayo, por ejemplo, una danza ceremonial Ilamada choqueo es frecuentemente realizada cuando se llevan a cabo encuentros de organizaciones indígenas financiados por la cooperación internacional y por organizaciones no gubernamentales (ONC) en interior de comunidades indígenas, en bloqueos de rutas y a veces en Asunción, la capital. Esta práctica ocurre espontáneamente, sin ningún previo y preestablecido arreglo por parte de las organizaciones de apoyo. Aun así, impresiona escasamente a la audiencia no indígena, que la etiqueta como manifestación "cultural", considerándola como un evento social dirigido a fortalecer los lazos entre los participantes indígenas, cumpliendo la misma función que una danza folklórica o un asado podrían tener en un contexto rural o urbano. El complejo conjunto de relaciones que enlazan conjuntamente el canto de la gente con los seres terrestres o espíritus auxiliares permanece oculto ${ }^{3}$.

Tal como Bonifacio ha analizado en un artículo (2013b), el trabajo de Prodechaco con organizaciones indígenas apuntaba al fortalecimiento de sus capacidades técnicas, las cuales eran vistas como la habilidad necesaria para escribir un "marco lógico", de manera que ellas fuesen capaces de solicitar autónomamente financiamiento a las organizaciones de desarrollo europeas. Este objetivo era compartido por otras entidades, como la cTz alemana, que organizaba talleres a fin de enseñar a los representantes indígenas como formular "proyectos" en términos técnicos apropiados. Mientras que una rama específica de Prodechaco estaba a cargo de potenciar la producción agrícola en las comunidades indígenas, otra rama estaba a cargo de apoyar y estimular la creación de organizaciones indígenas. La forma que las organizaciones indígenas tomaron - con su énfasis en la habilidad para dominar el lenguaje técnico de la cooperación internacional-era así el resultado de un encuentro cooperación recíproca entre líderes indígenas y funcionarios europeos. El desbalance de poder que marcaba esta relación, desde un punto de vista económico, es evidente, y las organizaciones indígenas muchas veces cumplían las expectativas de sus agencias financiadoras por medio de la adopción de un conjunto de palabras, de modo a concretar una profecía de autocumplimiento. La conservación de la naturaleza y la autosuficiencia económica eran expresiones cuyo significado no era completamente claro, o no era entendido del mismo modo por los indígenas y los no indígenas (¿Acaso una oficina totalmente equipada significa 'autode-
3 Véase Villagra (2009: 244258), del por qué el choqueo convoca la presencia de estos seres. 
terminación indígena’? ¿Qué más significa?). En comparación con otras organizaciones, los líderes indígenas apreciaban en Prodechaco la posibilidad de recibir la suma total del dinero que necesitaban para organizar sus reuniones con anterioridad al tiempo en que estas se realizaban. Organizaciones locales, de hecho, usualmente facilitaban las reuniones sin facilitar el dinero directamente a los líderes. El dinero era un símbolo de poder y un interminable tópico de discusión, pero también era considerado la mayor fuente de decadencia moral y de tensiones, entorpeciendo la habilidad de mantener unidas a las organizaciones indígenas a largo plazo (Blaser, 2010).

Al mismo tiempo, como el caso de Villagra ilustrará, las onc locales paraguayas se involucran en un conjunto de prácticas y relaciones que derivan de un tipo diferente de intimidad, una basada en una agenda política y cultural (supuestamente) común con las organizaciones indígenas, sea esta la lucha por derechos territoriales o por el autodesarrollo. El primer objetivo, asumido por ONC como Tierraviva, era y es perseguido dando el apoyo legal y reivindicativo a las comunidades indígenas con sus reclamos de tierra. Sea en el terreno -en las comunidades sin tierra y dentro de las estancias ganaderas que las han invadido y cercado - o ante las autoridades competentes y el público en general, los líderes indígenas deben asumir un discurso de confrontación, basado en la articulación de su diferencia étnica y cultural afirmativa, sus derechos legalmente reconocidos y la denuncia de su pobreza. Tierraviva apoya a los líderes en la construcción de tal discurso y su sostenibilidad; al mismo tiempo, como medios para ese fin principal, ella lleva a cabo otras tareas y atiende otras demandas indígenas ante el Estado (tales como asistencia humanitaria en tiempos de inundaciones; o la gestión de servicios de salud, alimento y educación). Las prácticas tales como el chamanismo, el uso y promoción del idioma propio, y la práctica (o revitalización) de rituales como el choqueo, han sido aceptadas por la onc como partes intrínsecas de la lucha política por la tierra. No obstante, no se consideran las prácticas citadas como necesarias y vitalmente parte del proceso político, tal como los pueblos indígenas ciertamente las consideraban y consideran, y como será ilustrado más abajo.

\section{HACIA UNA REDEFINICIÓN DE LA ARENA POLÍTICA EN TERRITORIO RIACHO MOS- QUITO A TRAVÉS DE LA FIGURA HISTÓRICA DEL CACIQUE MICHI}

Esta sección se basa en la experiencia de uno de nosotros, la de Valentina Bonifacio ${ }^{4}$, dada en un primer momento con la cooperación internacional y posteriormente, con las comunidades maskoy del Alto Paraguay 5 . Lo que se propone establecer es si existe una relación entre la falta de una organización indígena estable formalmente reconocida entre los maskoy residentes en el
4 Conforme a esto, de aquí en adelante, la narración en primera persona en esta sección se refiere a dicha experiencia y reflexión personal. Asimismo, a lo largo del texto y en los casos que la reflexión es de ambos autores, se usa la primera persona plural.

5 Esta investigación fue posible gracias al financiamiento de un beca de Marie Curie International Outgoing Fellowship (IOF), dada en el marco del séptimo programa cuadro de la Unión Europea "Crant agreement N. 628519". 
área y la proliferación de bailes de iniciación femenina, que se dieron a partir de la recuperación de la tierra en los años $80^{6}$. La respuesta a esta cuestión, si bien nunca podrá ser definitoria o categórica, implica repensar radicalmente el rol de la cooperación internacional y su definición de lo que constituye el desarrollo económico, por un lado, y los procesos políticos, por el otro. Para llevar esto a cabo, es necesario buscar y evidenciar los momentos de "equivocación" o desentendimientos recíprocos que se dieron entre la sociedad maskoy y sus intérpretes no-maskoy, a fin de poder no necesariamente "explicar, justificar, generalizar o interpretar" (Viveiros de Castro, 2015: 57), sino más bien establecer la duda para que, a partir de la misma, puedan surgir nuevas preguntas y conexiones.

No es mi intención, con este argumento, desvalorizar el papel de las ONG y sus campos de acción, cuyo apoyo a las organizaciones indígenas ha aportado victorias fundamentales de reapropiación de tierras ancestrales indígenas. Mi intención es, más bien, valorizar el papel de los rituales y ceremonias religiosas, considerándolas como eventos políticos que ratifican y reanudan las alianzas entre la gente del plano terrestre y los dueños de las cosas de mundos y niveles no visibles.

El Distrito La Victoria, del Alto Paraguay, en donde se ubica el territorio maskoy, se encuentra hoy - en el año 2016 - al centro de la producción ganadera, que se viene desarrollando en los últimos años a una velocidad sorprendente y avasallante en todo el norte del Chaco Paraguayo (Verijdt, 2013). Al mismo tiempo, está ubicado al margen de la atención de la clase urbana y de las instituciones gubernamentales ubicadas en la capital (no del Estado en general, que se hace presente a través de la Gobernación de Alto Paraguay y de la Municipalidad de Puerto Casado). Lo más relevante para este artículo y sección es que las comunidades maskoy están ubicadas en la periferia del espectro de acción de las ONC que se involucran con organizaciones indígenas en Paraguay, cuya atención en el Chaco se concentra en otras regiones. Esta situación de marginalidad está ejemplificada en el hecho de que no hay —ni en la realidad y ni en papel—una organización indígena maskoy, a diferencia de lo que pasa y se da con y entre otros grupos étnicos en el Chaco, que sí tienen organizaciones indígenas apoyadas económicamente por las onc indigenistas y/o ambientalistas.

Esta condición de aislamiento de los maskoy del ámbito de las organizaciones de desarrollo se debe probablemente a diferentes factores, cuyo orden de importancia e incidencia recíproca no es tan claro: el efectivo aislamiento geográfico; la recuperación de parte de sus tierras ya en los años 80; la presencia histórica, en el lugar, de una misión salesiana; y el hecho de ser un grupo étnico de reciente etnogénesis y reconocimiento oficial, por citar los factores más evidentes. Es solo en la época de la lucha por la tierra de los 80, de hecho, que ser maskoy se vuelve una referencia identitaria para individuos pertenecientes
6 En los años 80, se produjo una alianza política entre los maskoy y el Equipo Nacional de Misiones de la Iglesia Católica para llevar adelante el reclamo de tierras con la asesoría legal de la finada Abog. Mirna Vázquez, y René Ramírez - que en aquel momento era un joven catequista-fue elegido cacique general de los maskoy. También se conformó una comisión del pueblo maskoy que viajaba periódicamente a Asunción para pelear su causa con los políticos y generales que tenían autoridad y poder de decisión en aquella época. Esa organización comunitaria alrededor de Ramírez se disuelve una vez conseguida la tierra, cuando él deja su papel de cacique general y entra a militar en el partido político Liberal (para una descripción más detallada de ese proceso ver: Bonifacio, 2013a). 
a diferentes grupos indígenas que habían trabajado juntos para una empresa taninera argentina, la Carlos Casado s.A., por casi 100 años (Bonifacio y Villagra, 2015). En el año 1987, gracias a esa lucha, se titulan más de 30.000 hectáreas de tierra bajo el nombre de "Territorio Indígena maskoy de Riacho Mosquito". Hubo un tentativo fallido, del Prodechaco, de conformar una organización maskoy que abarcara también la comunidad de Casanillo, del Chaco central, pero cuando yo empecé a trabajar en el proyecto europeo, en el año 2004, tal iniciativa ya no estaba funcionando.

El hecho de no tener una organización indígena formalmente reconocida no significa que las comunidades no estén organizadas: desde 1981, con la promulgación de la Ley 904, cada una de las cinco comunidades maskoy tiene un líder oficialmente reconocido por el Instituto Paraguayo del Indígena (INDI). Adoptando una terminología matizada por Villagra, respecto a las variantes pasadas y presentes de los liderazgos de los grupos de la familia lingüística enlhet-enenlhet, podríamos decir que hubo una transición, en las últimas décadas, de un liderazgo de tipo "tradicional" — en donde las redes de parentesco, la generosidad, la valentía y las habilidades retóricas y chamánicas eran las más valoradas-a uno de tipo "transaccional", en donde la característica más valorada es la capacidad de mediar entre la comunidad y la sociedad no-indígena (Villagra, 2008). Al mismo tiempo, se fue separando y diferenciando, en personas y roles diferentes, el rol de líder político de aquél de los chamanes (Santos-Granero, 1986; Brown, 1993), así como también de los de "maestros de ceremonia".

Volviendo a la cuestión inicial, a pesar de que nunca se creó una organización indígena maskoy que funcionara y que fuera configurada según el planteamiento moderno de las oenegés, sí se multiplicaron - a partir de la recuperación de las tierras en 1987- los bailes de iniciación femenina (baile kuña o baile de la mujer, en el guaraní hablado por los maskoy), incrementándose su número exponencialmente con el transcurso de los años. En los primeros siete meses del 2016, se han realizado tres ceremonias en tres de las cinco comunidades existentes en las tierras o complejo de Riacho Mosquito, siempre en correspondencia con las vacaciones escolares y, en cada ocasión, gente de todas las comunidades se ha reunido en el lugar convenido. Los bailes, que duran una semana e implican una organización muy compleja, surgen de la voluntad de los padres de festejar la iniciación a la edad adulta de sus hijas, de la disponibilidad del líder a hacerse cargo del abastecimiento de víveres por el periodo del baile, y de la disponibilidad de los maestros de ceremonia a guiar el ritual. A pesar de que estos pertenecieran a dos grupos étnicos en particular, los guana y sanapaná, todos los habitantes, sin distinción étnica, participan hoy en los rituales, y parientes toba o enenl het, que vienen de otra comunidad alejada del Chaco central (Casanillo), también están empezando a participar en ellos. Para 
entender la relación entre los rituales, la disponibilidad alimentaria y la esfera política es necesario volver hacia atrás en la historia, hasta llegar a la figura del cacique Michi.

En el diario de su segunda expedición al Chaco del norte, en 1879, el explorador Juan de Cominges dedica varias páginas a la descripción de un tal cacique Michi (pequeño en guaraní) cuya toldería se encontraba sobre la ribera occidental del río Paraguay y prácticamente en la base de lo que hoy se proyecta como el territorio maskoy (Cominges, 1882). En la actualidad, y a pesar de que probablemente no se trate de la misma persona, el recuerdo y evocación de quizás otro líder homónimo, por ende también apodado Michi, aparece de forma destacada en los relatos de diferentes habitantes del área de Puerto Casado. Don Vásquez, un indígena que trabajó en la huerta de la empresa Carlos Casado S.A. en el KM 40 del ferrocarril, así recuerda su presencia en el territorio:

El cacique Michi vivía en un asentamiento de cinco o seis familias, en KM 46. Ellos se manejaban alli. Allí tenían su chacrita, y sus perros para ir a cazar... y también, no sé de donde habrían aprendido ellos, hacían miel de caña. Ellos lo que más comen es poroto y batata [...] Se suele ver [el cacique] porque él retiraba carne de nosotros, cada ocho días faenábamos una vaca y se le daba cabeza o chura [intestinos]. Se le daba así nomás, porque era indigena, él no tenía cuenta [con la empresa Casado] porque trabajaba por su cuenta (entrevista con Don Vásquez, realizada en Junio 2016).

La independencia del cacique y el trato respetuoso de la empresa hacia él se repiten en los relatos de René Ramírez, cacique general de los maskoy en la lucha por la tierra, quién recuerda haber conocido a Michi de niño. En los años 50, justo antes de su muerte, la toldería de Michi y de su gente se encontraba en un lugar denominado Ko Arta o Cruz Alta, a unos seis kilómetros de lo que es hoy la comunidad maskoy de км 40. Según los testimonios de varias personas maskoy, el cacique vivía en ese lugar con su esposa (al principio, con su gente; después, solo), y se dedicaba al cultivo de varias especies vegetales. Periódicamente se iba a vender sus productos en KM 39 del ferrocarril, en donde la empresa Carlos Casado s.A. tenía un almacén o tienda general. Esa imagen de "cacique agricultor" se opone claramente al estereotipo según el cual los indígenas angaité son tradicionalmente cazadores-recolectores que se dedican poco o nada a los cultivos. Hace también de contrapunto a la situación actual de las comunidades maskoy, en donde ya casi no hay producción agrícola. En los años 90, los esfuerzos de la cooperación internacional, a través de Prodechaco, para implementar una huerta comunitaria, de hecho, no llevaron a ningún resultado, siendo más bien una fuente de frustración y desconformidad para los técnicos del proyecto. 
En una conversación con René Ramírez y con uno de los nietos de Michi —que suponemos ser el homónimo y no el citado por Cominges, de acuerdo a una escala genealógica y temporal más ajustada—, Ilevada a cabo en el barrio indígena de Puerto Casado, Ilamado Pueblito Livio Fariña, ambas personas recordaron la enorme huerta de este cacique. En la misma, durante las distintas épocas del año, crecía un sinnúmero de productos en abundancia, y René y el referido nieto enumeraban: "tenía mamón, tenía naranja, pomelo, tenía todo... bananas, mandioca, piña, todo tenía. Estaban entre dos [él y su esposa] y tenían todo... ¿Cómo puede ser eso? Si nosotros lo vamos a hacer, no vamos a tener la cantidad que él tenía. Porque tiene espíritus... tiene sus hijos [otra manera de nominar a los espíritus auxiliares] que le ayudan a trabajar" (Entrevista con René Ramírez y con un nieto del cacique Michí, realizada en 25 de Junio de 2015). Según Ramírez, Michi era chamán y era uno de los mejores "con la adivinación" (Entrevista con René Ramírez 10 de agosto de 2007), y es por esa razón que el dueño de la empresa Casado iba a verlo para pedirle noticias sobre las condiciones de salud de sus familiares que se encontraban lejos de Paraguay. No solamente el cacique Michi vendía a los paraguayos —nominal y étnicamente diferenciados de los indígenas- los productos que sus espíritus auxiliares le ayudaban a cultivar, sino que era el único indígena en ese momento que tenía tierra propia y a su nombre, tierra esta que la misma familia Casado le había regalado en razón del respeto que le tenía. Ramírez asevera y da por seguro que el INDI guarda, entre sus archivos, ese título de tierra, el cual testimonia la alianza política entre aquel cacique y la empresa.

Otros maskoy, no obstante, presentan una visión más conflictiva de esa relación. Según Varcilicio Ojeda —él también identificándose como nieto de Michi- el cacique ya tenía vacas cuando los paraguayos todavía no tenían ninguna. Por esa razón, la empresa Casado s.A. mandó a un mayordomo de estancia, Cirilo Soto, a que le robé su ganado. Varcilicio Ojeda también recuerda la chacra de Michi: las batatas dulces, los mangos, las mandarinas, los limones y la papaya, siendo su descripción solo ligeramente diferente de la de Ramírez, ambos poblando los cultivos con todos los frutos agrícolas que podían imaginar y nombrar. Pero hay otro detalle importante, Ojeda también recuerda que el cacique solía preparar la chicha a base de miel, que era utilizada por la gente en los rituales de iniciación femenina (entrevista con Ojeda, realizada en 2 de septiembre de 2015). Así se completa la imagen del cacique Michi, en cuya chacra todos los productos crecían prolíficamente gracias a sus espíritus auxiliares, lo que atestigua sus grandes poderes chamánicos, siendo ambos (alimentos y alianza con espíritus auxiliares) fundamentales para los rituales y fiestas de iniciación; también su reconocimiento como líder, por parte de los patrones de la empresa Casado — quienes incluso le regalaron un caballo, sin ninguna razón aparente- 
es prueba de aquellos poderes (entrevista con Ojeda, 2 de septiembre de 2015).

Mi argumento central en este artículo y sección es que la cooperación internacional intenta separar lo que Michi lograba unificar en su figura, y que los bailes de iniciación, que hoy proliferan en las comunidades maskoy, aspiran a reafirmar alianzas, tejiendo relaciones entre varios seres: la relación entre la esfera política, los espíritus del monte y de las plantas, y la capacidad de obtener sustento del territorio cosmopolítico en el que se habita. Los rituales de iniciación femenina tienen la capacidad (entre otras) de crear y sostener la comunidad "política" que, en otros contextos, se crea y sostiene a través de organizaciones indígenas oficialmente reconocidas y financiadas por la cooperación internacional (Bonifacio, 2013b). Al mismo tiempo, reactivando la relación con los espíritus del monte y de las plantas, esos rituales sugieren un camino para "hallarse" (estar contentos), que permite salir de la dependencia económica, reconectarse con el territorio y encaminarse hacia la "libertad". "Libertad" es la palabra utilizada por otro líder maskoy, Juan Conzales, quién hablaba de la necesidad y condición de tener tierra propia restituida para poder realizar los rituales (Bonifacio, 2009). Alternativamente, podríamos utilizar la palabra "autodeterminación", si quisiéramos hablar el idioma de la cooperación internacional y las onc. Separando la esfera política (a través de la creación de organizaciones indígenas) y la esfera económica (a través del apoyo técnico a la producción agrícola), la cooperación internacional separa lo que los rituales unen.

Cincuenta años después la muerte del cacique Michi (o de su homónimo sucesor) y en la primera década de este siglo, los cultivos son escasos o marginales en las comunidades maskoy, y la obtención de comida del monte es poca, a la par que está minusvalorada o dejada de lado, como práctica del pasado, siendo la comida manufacturada de los "blancos" —la harina, los fideos y las galletas, entre otros-el alimento mayormente disponible. Los bailes de iniciación femenina y otros bailes antiguos, retomados con fuerza a partir de la recuperación de la tierra, en los 80 (Delporte, 1992), se sostienen gracias a la red de clientelismo político local y al apoyo de los políticos de turno, así como a los subsidios estatales, que permiten comprar harina, arroz y galletas en los almacenes de Puerto Casado. Con suerte, estos alimentos se complementan con el faenamiento de un animal vacuno, que alguna organización indigenista esporádicamente entrega a través de algún proyecto a las comunidades maskoy. En algunos casos, los chamanes "trabajan" para "aflojar" a los políticos y estimularlos a ser generosos con los líderes políticos indígenas oficiales (Bonifacio, 2013b).

Hablando de los cambios acontecidos en las comunidades nivacle del Chaco central, dos antropólogos que han dedicado toda su vida al estudio de los grupos indígenas del Chaco — Miguel Chase-Sardi y Branislava Susnik—apuntan que: 
Los Nivacle [sic] poseían una rica horticultura, principalmente, para la preparación de las bebidas que se consumían en las fiestas de imposición del cacicazgo, e iniciación de las niñas púberes. Pero, el hecho de que algunas de las mas bellas mujeres se desnudaran frente al líder, y algunas libertades que los jóvenes se tomaban durante la celebración de la iniciación, escandalizaron el puritanismo de los misioneros y estos prohibieron las ceremonias religiosas indígenas. Terminado el incentivo para la horticultura esta decayó, y, pocos años después, solo se veían algunos metros cuadrados cultivados por unos pocos viejos (Chase-Sardiy Susnik, 1995: 261).

Varias décadas antes, hablando de los pobladores de las islas Trobriand en Melanesia, Malinowski hace consideraciones parecidas. Comienza describiendo la incapacidad de los jefes trobriandeses para organizar grandes banquetes, a causa de su decadencia política y económica que fuera generada por la colonización europea, y sigue argumentando que impedir la organización de esas ceremonias

lo[s] priva de muchas de sus más queridas diversiones, de sus maneras de disfrutar de la vida, y de los placeres sociales. Ahora, una vez hecha la vida no atractiva para un individuo, sea salvaje o civilizado, se está cortando las raíces de su vitalidad (Malinowski, 2005: 367, traducción de los autores).

Con un tono aún más dramático, Malinowski concluye que la negación de aquello que les da sentido "podría resultar en el abandono del deseo de vivir en general" de los nativos (Malinowski, 2005: 367; traducción de los autores). Aunque formulado con un tono más templado, la mención de Susnik y Chase-Sardi a los rituales como "incentivo para cultivar" hace referencia también a una configuración afectiva fundamental: la relación entre la felicidad y/o plenitud, las ceremonias y la producción agrícola. Indirectamente, esa configuración nos acerca también al papel que De la Cadena define como "interacciones afectivas, no-representacionales, con otros [seres] no-humanos" (2010: 346). Distinguiendo el ámbito técnico/productivo del ámbito político/organizativo, y enfrentándolos por separado, la cooperación internacional vuelve invisible la relación entre ambos y pierde el contacto con el núcleo de afectividad que los sostiene. Esta separación tiene que ver, por otro lado, con la división "moderna" subrayada por Bruno Latour (1990) entre la "ciencia de las personas [la política]" y la "ciencia de la naturaleza". De la misma forma, la lógica burocrática asume que la ciencia de la naturaleza —en este caso, la agronomía — por sí misma tiene que encargarse de fomentar y solucionar los problemas relacionados con la producción agrícola, y que la ciencia de las personas — la democracia — tiene que encargarse, ella 
sola, de organizar de manera eficiente la sociedad. La aparición de los kamba (hombres enmascarados, literalmente: "negros" en guaraní paraguayo), también denominados también "zapallos", en el baile kuña maskoy, nos obliga a cuestionar esa lógica. Si miramos, por ejemplo, a un zapallo simplemente como una "hortaliza", sin tomar en cuenta la forma que asume en ciertos rituales a través de su apropiación mimética por parte de los danzadores, y si olvidamos que los espíritus de los animales, plantas silvestres y productos agrícolas se manifiestan y hacen presentes en los rituales a través del canto, no estamos viendo el mismo zapallo que crecía en la huerta del cacique Michi, en la época en que este lo cultivaba con la ayuda de sus espíritus auxiliares.

Después de varios años de trabajo con las comunidades maskoy, Prodechaco no consiguió ni lograr la creación de una organización indígena oficialmente reconocida y operante (aunque sí consiguió obtener la personería jurídica para una organización que tuvo una existencia muy efímera) ni una producción agrícola significativa y sustentable. Mi argumento en este artículo y sección es que fue gracias al "abandono" de la cooperación internacional y a la no implementación de una organización indígena "moderna" (en el sentido latouriano de la palabra) que los rituales de iniciación son, hoy en día, el centro de la vida comunitaria de las comunidades maskoy, como su modo de volver a conectar relaciones interrumpidas y de redefinir la arena política a partir de otra perspectiva y a través de la alegría del baile.

\section{INFLUYENDO A LOS POLÍTICOS DEL CONGRESO CON LOS SERES-AUXILIARES DE LOS MÚLTIPLES NIVELES DEL COSMOS: LAS DERROTAS Y LAS VICTORIAS DE LOS CHAMA- NES SANAPANÁ Y ENXET EN EL CASO DE LA REIVINDICACIÓN DE XAKMOK KÁSEK}

Este caso y sección se basa en la experiencia y etnografía del autor Rodrigo Villagra, como parte de la organización no gubernamental Tierraviva. A finales del año 2000, la reivindicación territorial de la comunidad Xakmók Kásek, conformada por familias sanapaná y enxet, iba ganando el punto de discusión más trascendente y controvertido en interior de la Cámara de Senadores y en los medios de comunicación. Apoyada por la organización no gubernamental Tierraviva, la comunidad reclamaba, en ese entonces, unas 10.700 hectáreas de tierra que representaban solo una pequeña porción de su territorio ancestral, pero que fueron el núcleo de su hábitat tradicional en las últimas décadas.

En particular, enfatizaba en su reclamo que la privación histórica de esas tierras los habían condenado a la pobreza, la explotación laboral, la alienación cultural y a pésimas condiciones de vida y de salud; y que el Instituto Paraguayo del Indígena (INDI) y el Instituto de Desarrollo Rural (Indert) habían fracasado en dar una solución al caso, desde que el mismo se presentó oficialmente, por 
primera vez, en el año $1986^{7}$.

La comunidad Xakmok Kásek y sus aliados agregaban que este fracaso era inexcusable e inconcebible teniendo en cuenta las leyes y normas a favor de los derechos indígenas vigentes en Paraguay: la Ley Nº 904/1981, el Convenio No 169 de la Organización Internacional del Trabajo (оІт) y el Capítulo Quinto de la Constitución Nacional sobre los derechos de los pueblos indígenas. Este último, por ejemplo, reconocía el principio de la preexistencia de los pueblos indígenas al Estado paraguayo, así como su derecho a la propiedad comunitaria en extensión y calidad suficientes para la conservación y desarrollo de sus formas peculiares de vida.

Por su parte, el terrateniente y propietario de la Estancia Salazar, el señor Robert Eaton (hijo), alegaba que las 10.700 hectáreas exigidas en restitución por la comunidad era el "corazón productivo" de su establecimiento ganadero. Dicha estancia se había establecido a inicios de la década de los 40 del siglo pasado y había llegado a tener más de 109.000 hectáreas en su conjunto, cercando y englobando la mayor parte del territorio y hábitat tradicional de las aldeas indígenas de la zona. A la par, los propietarios y titulares principales de la estancia Salazar -Eaton padre y luego su hijo - habían concentrado a esta población indígena a un espacio muy reducido — de menos de 4 hectáreas-al margen del casco principal, a fin de controlarla y utilizarla como mano de obra barata para manejo de su ganado.

El Sr. Eaton y sus abogados alegaban también que la Constitución de la República del Paraguay protegía firmemente la inviolabilidad del derecho a la propiedad privada en su artículo 107, y que la Ley del Estatuto Agario No 2419/2014 establecía claramente que las tierras que estaban racionalmente explotadas por sus propietarios deberían ser protegidas y no podían, en ningún caso, ser expropiadas a los mismos. El Sr. Eaton, asimismo, negaba las denuncias de explotación laboral y de condiciones de vida infrahumanas, arguyendo que los trabajadores y familias indígenas residentes en la estancia Salazar eran tratados con justicia y conforme a la ley laboral ${ }^{8}$.

El debate era avivado públicamente con estos y otros alegatos de cada parte. La comunidad y sus abogados presentaron los hechos y datos que probaron la ocupación ancestral de las tierras en un dossier de documentos que fue distribuido a senadores y periodistas. Uno de los documentos claves era el informe y laudo antropológico del antropólogo Miguel Chase-Sardi, que había escrito a favor de los reclamos de la comunidad Xakmok Kásek. En el informe, Chase-Sardi explicaba que, antes de la colonización paraguaya del territorio chaqueño, alrededor del año 1890, los pueblos sanapaná, enxet y angaité se distribuían en aquél territorio y zona específica —noroeste del actual departamento de Presidente Hayes - en pequeñas aldeas, y vivían de la caza, pesca, horticultura
7 Esta primera solicitud oficial, firmada por el entonces líder de la comunidad reconocido por el INDI Ramón Oviedo, también chamán, demandaba un número bastante reducido de hectáreas. El documento se perdió en los archivos del INDI y/o del Indert, por lo que, en el año 1993, se volvió a presentar una nueva solicitud y reivindicación de tierras, ya por un área mayor y conteste a la nueva legislación y normas vigentes.

8 Estas denuncias fueran incluso objeto de una demanda laboral por parte de los indígenas, que no llegó a término favorable por diversas razones y circunstancias, pero que al menos sirvió para que se equipararan salario y otros beneficios laborales debidos a los trabajadores indígenas con aquellos recibidos por el personal no indígena de la estancia — dado que, mismo en la planilla de pagos de la empresa Eaton y Cía. S.A., se anotaba como "indio" a cada trabajador indígena, apuntándose a estas personas un salario $40 \%$ inferior que aquel pago a los trabajadores no indígenas. 
y del trueque entre sí, e incluso con los no indígenas, realizado por medio del contacto y acceso a aldeas ribereñas del lado derecho del Río Paraguay, como la del cacique Mich.

Aun según el laudo de Chase-Sardi, en los tiempos estivales de cosecha y abundancia de comida, esos pueblos tenían grandes ceremonias y encuentros, como los aludidos por Bonifacio, tales como el waingka y el yammana, rituales de iniciación masculina y femenina respectivamente. El baile del choqueo era una de las diversas danzas, cantos y juegos practicados en esas ceremonias. En aquel tiempo, los wese o vese, en los idiomas enxet y sanapaná respectivamente, eran los líderes de las aldeas en quienes confluían tanto las capacidades políticas como chamánicas, que eran utilizadas para proveer de alimento y proteger de los enemigos humanos y meta-humanos a su gente. El informe resaltaba que estas características eran bastante diseminadas en aquel tiempo precolonial y todavía muy presentes en décadas posteriores, pero que luego de la Cuerra del Chaco (1932-1935), entre Paraguay y Bolivia, la situación cambió radicalmente.

En los tiempos modernos, apuntaba Chase-Sardi $-\mathrm{y}$ contemporáneos, apuntamos nosotros - hay escasos y/o irregulares rituales en Xakmok Kásek, así como en muchas otras comunidades que han sido encerradas en las estancias ganaderas. Igualmente, se ha producido un cambio lingüístico, con el abandono de las lenguas sanapaná y enxet, yendo hacia un uso preponderante del guaraní paraguayo. Además, las actividades tradicionales de subsistencia han sido fuertemente restringidas o prohibidas por el propio Eaton y ganaderos vecinos - de manera semejante a lo que ocurre en el resto del Chaco. Así también, se observaba y aún se constata una pobreza generalizada de las familias de la comunidad, debido a la discriminación y explotación laboral en la estancia Salazar, la falta de alimentación suficiente, el difícil acceso a la salud y al agua potable, aspectos estos resultantes de restricciones impuestas por Eaton y asimismo por la inasistencia histórica del Estado a la comunidad.

Otro documento en el dossier de apoyo del reclamo de la comunidad era un mapa en el cual se exhibían los topónimos - nombres de lugares y aldeas tradicionales - en los idiomas sanapaná y enxet, tales como el sitio principal de Mopey Sensap, "Mariposa Blanca". Se trata de una localidad mencionada en el informe de Chase-Sardi como el punto y centro principal a cuyo alrededor se encontraban las tierras habitadas y habitables demandadas en restitución por la comunidad.

Eaton hijo y sus abogados, por su parte, también prepararon y entregaron un dossier de documentos para validar, ante los parlamentarios, su posición de rechazo a la expropiación en su contra de las tierras reclamadas por los indígenas. En uno de estos documentos, Eaton, con un elevado entusiasmo, narraba como su padre, un joven norteamericano busca-fortunas, había llegado hacia los años 1920 al hostil Chaco para trabajar, junto con otros cowboys americanos e 
ingleses, para la International Products Corporation (IPC), una compañía ganadera y extractora del tanino de los abundantes arboles de quebracho colorado (Schinopsis Balansae) del suelo chaqueño.

Cabe aclarar, por nuestra parte, que el establecimiento principal de la IPC fue en Puerto Pinasco, fundado previamente en 1907, por otra compañía, sobre la ribera occidental del río Paraguay, a unos 100 kilómetros aproximadamente aguas abajo de Puerto Casado. Su fábrica de procesamiento y producción de tanino fue construida hacia 1917, luego que la IPC adquirió cerca de un millón de hectáreas que partían de una amplia franja sobre la ribera occidental del río y se extendían bastante lejos, hacia adentro y al oeste del Chaco. A partir de la construcción de una línea férrea con dos ejes —uno yendo hasta más de 100 kilómetros tierra adentro y en dirección oeste; y otro, de unos 60 kilómetros aproximadamente, hacia el suroeste- - la IPc extendió su control sobre las aldeas y tierras indígenas del interior, étnica y geográficamente heterogéneas (Bonifacio y Villagra, 2015), abriendo progresivamente estancias, obrajes madereros y puestos de avanzadas que alcanzaron los límites occidentales y el territorio poblado libremente por las aldeas de los ancestros de la comunidad Xakmok Kásek. Décadas más tarde, cuando la producción de tanino declinó y la IPC parceló y dividió sus tierras, el padre de Eaton, junto con otros exempleados y cowboys gringos, compró a un muy bajo precio las 109.000 hectáreas que irían formar la estancia Salazar.

Eaton hijo, en el documento aludido, quería probar que su padre era uno de los colonos pioneros del Chaco, y que como tal había contribuido a que se abran las puertas del progreso económico hacia las tierras interiores del Chaco. Contradictoriamente, si bien en alguna parte el alegato de defensa de su propiedad, reconocía la ayuda que los indígenas prestaron a la IPC y a su propio padre para abrir caminos, levantar estancias y manejar el ganado, y enfatizaba que estos habían sido siempre errantes y que carecían de iniciativa para el progreso y el trabajo. Con relación a la ocupación ancestral, Eaton argumentaba que los indígenas y sus familias habían venido de otros lugares y zonas a su estancia, buscando empleo. En lo que se refiere a sus actividades de subsistencia, de caza y de recolección, agregaba que eran nómadas y que, por lo tanto, en el pasado, nunca habitaron un territorio específico. Finalmente, subrayaba que demasiadas tierras ya habían sido restituidas a los indígenas del Chaco, y que en la mayoría de estas no se les daba un eficaz uso productivo. Además, para concluir, añadía que muchos ganaderos querían vender sus tierras en las cercanías o zona aledañas a su estancia, y no demasiado lejos del reclamo de la comunidad.

Hasta ese punto, la pelea y controversia había sido mayormente a nivel legal, siendo que ambas partes habían recogido evidencias y documentos para probar el mejor derecho al área de las 10.700 hectáreas en disputa. En ningún momen- 
to, los representantes y portavoces de la comunidad - es decir, los líderes legalmente reconocidos por el INDI-, ni nosotros, como abogados y acompañantes de la onc Tierraviva, hicimos una alusión directa a los chamanes y menos aún a los espíritus auxiliares de estos, como poblando e interactuando, en un sentido amplio y multidimensional, el territorio y las tierras reclamadas. Al menos de parte de Tierraviva, esta omisión no fue consciente, si bien puede que se haya llegado a notar o señalar, en al gún escrito argumentativo a favor del reclamo de tierra de la comunidad, que existía al menos un chamán activo en la comunidad cuyas opiniones eran prominentes - del mismo modo que se conocía la presencia de otros chamanes en otras comunidades. Más bien, los argumentos desarrollados como sustento y defensa del reclamo de Xakmok Kásek tenían que ver con aquello que podía ser "políticamente" relevante o estratégico para la lucha territorial —en ese sentido, las prácticas y aspectos culturales, como rituales pasados o toponimía en lengua vernácula, eran todos considerados y mencionados por nosotros como una suerte de "medios" o aspectos instrumentales para el fin principal, que era la obtención de las tierras. Es decir, estos aspectos no eran considerados esencialmente políticos; se reconocían, sí, como expresamente políticas, a las denuncias de los líderes reconocidos en contra de Eaton, o aquellas relativas a la inasistencia e inoperancia del Estado para tramitar el reclamo territorial y brindar protección judicial, así como para asistir a la comunidad en otras necesidades básicas, como agua, salud y alimentación.

Sin embargo, una omisión que hoy, a la distancia, considero más consciente, era la de la propia comunidad, sus integrantes y representantes, quienes, en sus manifestaciones públicas ante autoridades o periodistas, no traían a colación la existencia de los chamanes y, menos aún, el tipo de actividades y rol que estos podrían llegar a jugar con relación al reclamo territorial.

Cuando el trámite del Proyecto de ley de expropiación de las 10.700 hectáreas alcanzó el punto inminente, en el cual debía ser discutido por el plenario del Senado, luego de su discusión en comisiones de estudio especializadas del Senado, habiendo obtenido tanto un dictamen a favor como otro en contra, algunos líderes y miembros de la comunidad nos sugirieron que les ayudemos a organizar una reunión de chamanes. Los chamanes, una vez que fuesen puestos a trabajar en un lugar determinado, usarían sus poderes para influenciar a los senadores de modo a que ellos votasen a favor de la expropiación de tierras. Tanto Marcelino López —en ese momento, el líder principal y el portavoz más prominente de la comunidad — como la finada Antonia Ramírez — una mujer mayor, también de gran presencia comunitaria-dijeron a nosotros, sus aliados de Tierraviva, que el entonces vivo chamán enxet Enrique Cabañas —casado con una mujer sanapaná y de la comunidad La India, mayormente poblaba por la última etnia-era muy poderoso, al punto que podía hacer aparecer en frente 
de uno "cualquier cosa que uno quisiera". Cuando era joven, Enrique Cabañas fue uno de los baqueanos indígenas del ejército Paraguayo, siendo reclutado por un militar de mediano rango para ser guía de camino y luego, incluso, para ir al frente a pelear en contra de los bolivianos.

Conforme a la propuesta de la comunidad, aceptamos como onc, de buena gana, la sugerencia, así como la condición de que los chamanes deberían reunirse en las oficinas de la ONG, ubicada en Asunción, la capital. La propuesta era que se organizase una suerte de cónclave de chamanes: además del chamán invitado, Enrique Cabañas, así como del chamán residente de la comunidad, ambos de la etnia enxet ${ }^{9}$, también se propuso invitar a algunos chamanes que eran de la etnia sanapaná pero originalmente pobladores y parientes de las familias sanapaná de Xakmok Kásek que, luego de un conflicto interno, fueron a vivir a la comunidad Nueva Promesa y, después, a la comunidad La Palmera, como era el caso del chamán y ex-líder de Xakmok Kásek, Ramón Oviedo. Como parte del acuerdo, Tierraviva debía proveer el dinero para los pasajes de bus de ida y vuelta de los chamanes, un espacio para su alojamiento en la oficina, comida e incluso un pequeño pago en dinero por sus servicios.

Cuando los chamanes Ilegaron a Asunción, conforme a la invitación y número esperado — unos cinco o seis, si mal no recuerdo—- pidieron que se les asigne un lugar tranquilo y cerrado para trabajar —estrictamente a la noche-, y se les dio para ello la sala de reuniones ubicada en un segundo piso. Asimismo, los chamanes pidieron hacer visitas cortas al Parlamento, lo que se hizo un par de veces. Al Ilegar al Parlamento, no quisieron entrar al edificio del Senado, sino que prefirieron ubicarse a unas decenas de metros de la entrada, calladamente y sentados en un plaza frontal al edificio, de manera a pasar inadvertidos e identificar, a su voluntad, a los senadores que iban entrando y saliendo, quienes serían más tarde el "blanco" de sus trabajos chamánicos.

Noche a noche, los cinco o seis chamanes, probablemente cantando y en trance, se juntaban en el segundo piso de la oficina de la ONG, donde encontraban a sus seres auxiliares, a quienes les decían que hacer de modo a penetrar en el wáxok (estómago/corazón) ${ }^{10}$ de los senadores ${ }^{11}$, Ilenándoles con el deseo de votar a favor del reclamo de tierra comunitario al tiempo que esto ocurriera en el plenario de la Cámara. De día, los chamanes dormían y erraban al interior de la oficina, o se paraban en la vereda frente a ella, sin mayor afán o preocupación. Recuerdo una o dos reuniones llevadas a cabo con ellos, los líderes comunitarios y el equipo de trabajo y abogados de la onc. En una de ellas, uno de los chamanes dijo que "ipoima ore pytu" —en guaraní, se traduciría cómo nuestro aliento/anima es muy "fino" - dicho en el sentido que todos ellos estaban haciendo un esfuerzo muy grande cada noche - físico y metafísico a la vez-entrando en contacto, a través del canto, trance y viaje, con sus "socios" o seres auxiliares.
9 El abuelo del finado chamán Juan Dermott fue Edward Dermott, un médico irlandés contratado por la misión de la Iglesia Anglicana que vino al Paraguay con su esposa y tres hijos a inicios del siglo XX. Dicha misión tenía personal y misioneros mayormente de origen inglés - aunque su misionero más prominente fue un escoses, Warbrooke Crubb. La sede central de la misión inglesa fue la co-munidad Makxawaya. El padre de Juan, un joven de 18 años cuando llegara a Paraguay, se casó con una mujer enxet, con quién tuvo 10 hijos. Todas las hijas mujeres de la pareja se casaron con paraguayos "chaqueños" —criollosy los hombres, cómo Juan y sus hermanos Félixy Tomás, fueron y quedaron a vivir en la comunidad indígena de Xakmok Kásek u otras aldeas de población mayoritaria indígena - como la estancia Pozo Verde, propiedad de un pariente de Eaton-auto-identificándose como indígenas.

10 Centro cognoscitivo y afectivo de las personas, de acuerdo a los enxet, ubicado físicamente entre el estómago y el corazón. Véase Kidd (1999: 47-68)

11 Para una discusión sobre el papel de los chamanes en ablandar los políticos en la reivindicación de tierra maskoy, véase Bonifacio (2013a). 
Ese mismo chamán agregó que deberían ser cuidadosos con sus poderes, dado que podrían, accidentalmente y sin intención expresa, llegar a matar a algún senador, y esto podría ocasionar a su vez una retaliación hacia la comunidad por parte de los demás senadores.

No obstante, mi escepticismo creció en desmedro del beneficio de la duda que tenía, al principio, sobre la seriedad y eventual eficacia del procedimiento, cuando Enrique, quién oficiaba de chamán principal, tímidamente nos mostró a algunos miembros de la onc una foto del entonces presidente de la República, Luis Conzález Macchi, preguntándonos si era a él, o al menos uno de aquellos, a quienes había que influenciar. Mis dudas, al menos a ese respecto, eran atendibles - no tanto por la eficacia o no de todo el procedimiento chamánico- sino por el error de asumir como responsable al Presidente de la República, quién, al menos en la instancia de discusión del proyecto de ley de expropiación en el Senado, no tenía formalmente ninguna incidencia para la decisión final a ser tomada por la Cámara de Senadores.

El 16 de noviembre del año 2000, el plenario del Senado de Paraguay votó, por amplia mayoría, en contra del proyecto de expropiación del reclamo territorial de la comunidad Xakmok Kásek. Como aliados y propulsores del reclamo comunitario y de la campaña y trabajo de lobby que se había hecho en favor de la demanda, estábamos abatidos y desconcertados, dado que en aquel entonces no existía, a nivel interno de Paraguay, ninguna vía alternativa legal que pudiera efectivamente revertir esa decisión y posibilitar a su vez que la comunidad, y a nosotros como onc acompañándola, podamos recuperar primero y luego titular las tierras reclamadas por Xakmok Kásek.

Cabe mencionar que la discusión en el plenario del Senado que concluyó con esa decisión alcanzó un nivel de absurdo y racismo inauditos. Un senador argumentó que los "los Indios no harían nada de valor con la tierra y que no sabían nada más que emborracharse". Asimismo, desconociéndose la naturaleza diferente del reclamo - tierras ancestrales indígenas como previo y mejor derecho frente a terceros - se tomó a rajatabla los alegatos de Eaton respecto a la explotación racional de la parte reclamada, el retiro Primero, siendo que esta parte había sido puesta a servicio de usos muy diversos, por lo que, ni aun utilizando el criterio de explotación racional — que era inapropiado, dado el carácter del caso-, podría justificarse la supuesta función productiva principal para el conjunto de la estancia.

Por otra parte, ante la decisión final, el propio líder principal de Xakmok Kásek, claramente frustrado y evaluando el trabajo de los chamanes, dijo que ellos eran "inútiles". Ante la contundencia del resultado negativo del momento, no se me ocurrió a mí ni a mis compañeros y compañeras de onc indagar más a los chamanes convocados sobre las razones del momentáneo fracaso de sus tra- 
bajos, poderes y seres auxiliares que participaron en aquella ocasión, o sobre de las dificultades encontradas al querer influir sobre los senadores. Ciertamente, esa derrota fue transitoria, desde una visión retrospectiva y teniendo en cuenta el actual curso favorable de la reivindicación.

Haciendo un resumen muy somero de numerosos hechos y acontecimientos, varios años más tarde, luego de también una larga prosecución de acciones, primero ante la Comisión Interamericana de Derechos Humanos (Comisión IDH), y luego ante la Corte Interamericana de Derechos Humanos (Corte IDH), esta última emitió el 24 de agosto del año 2010 una condena en contra del Estado paraguayo y a favor de la comunidad Xakmok Kásek, obligando al primero a que -entre otros puntos - recupere y titule las 10.700 hectáreas reclamadas en propiedad comunitaria. Esta sentencia y condena abrió el camino a nuevas negociaciones con el Estado, en los sucesivos gobiernos que han ido turnándose en el poder desde entonces. El INDI, por su parte y en el marco de estas negociaciones, incluyó en su presupuesto anual del año 2015 y luego en el de 2016 un monto específico destinado al pago de las tierras reclamadas y en concepto de indemnización a los propietarios, cuya cabeza visible se constituyó en otra persona, el Sr. Mobsby, dado que Eaton hijo fue desplazado de la representación de los socios de las empresas a cuyos nombres se habían titulado las tierras y la estancia Zalazar.

Desde el 2015, la mayoría de las familias de la comunidad decidió, como medida de presión y apropiación, y dada las dilaciones hasta ese entonces de los órganos e instancias estatales, para resolver el caso conforme a la sentencia de la Corte IDH, reocupando el área específica de Mopey Sensap o Retiro Primero, de 7.700 hectáreas. Por lo que pude informarme, sin tener acceso al día a día de las gestiones del caso, supe que los chamanes, incluso habiendo ya fallecido hace unos años Juan Dermott y Enrique Cabañas, no quedaron de brazos cruzados, a pesar de aquella primera y aparente derrota definitiva ante el Senado paraguayo.

Laureano Ayala, por ejemplo, un chamán indígena de ascendencia enxet y angaité - miembro y en algún momento presidente de la Coordinadora de Líderes Indígenas del Bajo Chaco (Clibch), una organización indígena que reúne a representantes de comunidades angaité, enxet, sanapaná y toba qom del Bajo Chaco o departamento de Presidente Hayes — ratificó a personas del equipo de trabajo de Tierraviva que él y otros chamanes habían venido trabajando, a lo largo de estos años, para influenciar con sus poderes y modificar la actitud y disposición contraria de las autoridades sobre este y otros reclamos de tierra indígenas del Bajo Chaco que también contaban con sentencias de la Corte IDH a favor de las comunidades y en contra del estado, como los casos de Yakye Axa, Sawhoyamaxa y Kelymagategma ${ }^{12}$. Este trabajo, si bien menos conspicuo y paralelo a las manifestaciones públicas y acciones directas de la comunidad

12 Véase los casos señalados en el portal de la Corte IDH: http:// www.corteidh.or.cr/cf/jurisprudenciaz/casos_en_etapa_de_supervision.cfm, recuperado el 31/08/2016. 
- como eran la reocupación de sus tierras, la representación, negociación y presión continúa de los líderes, y las gestiones y acciones jurídico-político de la comunidad-fue constante.

En mi caso, ya en estos últimos tiempos definitorios del proceso (y de redacción del presente trabajo), en concreto, en un viaje realizado en el mes de abril del 2016 a otra comunidad, La Patria, en cuyo camino de acceso se encontraban también las tierras y la ocupación de las familias de Xakmok Kásek, y en el que fuimos acompañados por el chamán Laureano y por otros líderes y miembros de Tierraviva, pude observar la intervención chamánica del primero. Era de tarde, y hombres, mujeres y niños de la comunidad esperaban, al costado del camino de tierra y en el portón de acceso al retiro Primero, dos buses, alquilados por Tierraviva, que los Ilevarían a Asunción a fin de manifestarse frente al local del Ministerio de Hacienda, donde iban a demandar que dicho organismo liberase finalmente los fondos del presupuesto para que se realizara el primer de los tres pagos programados para indemnizar a los titulares de la estancia Salazar. Laureano se bajó del vehículo en que íbamos y, luego de los saludos de rigor a los líderes de Xakmok Kásek y a algunos conocidos, dijo que iba a hacer un canto para dar fuerza para el viaje y para que las autoridades de Asunción escuchen y obren a favor de los pedidos de la comunidad. El canto fue breve y seguimos viaje. Una noche más tarde, en el contexto de un choqueo y un poco excitados por la ingestión de alcohol, Laureano nos dijo que iba a enviar un "terremoto" a Asunción —al igual del que había ocurrido recientemente en Ecuador - a fin de doblegar la indisposición de los políticos y, por extensión, de los no indígenas habitantes de la capital — ciudad que era identificada como el centro del poder y de toma de decisiones del país - para que se escucharan las demandas indígenas.

Si bien el fenómeno climático anunciado no ocurrió, luego de innumerables dificultades y teniendo en cuenta un contexto general de políticas públicas negativas — siendo el propio presidente de la República contrario a restitución de tierras indígenas adicionales-, puede decirse que hubo una suerte de movimiento telúrico en el ámbito político, al darse finalmente darse las condiciones necesarias para que el reclamo territorial de Xakmok Kásek se resuelva definitivamente ${ }^{13}$. Conforme a esto, podemos concluir que los chamanes enxet y sanapaná han seguido actuando con sus seres auxiliares y que, esta vez, su hálito y cantos resuenan a victoria.

13 Véase la información reciente del caso en http://www.tierraviva. org.py/?page_id=2128, recuperado el 28/09/2016.

\section{CONCLUSIONES}

Los dos contextos tomados en cuenta en este artículo relatan dos situaciones en las que seres no-humanos - a los que convenimos en llamar "espíritus 
auxiliares", abarcando a las distintas formas y denominaciones que toman a nivel local — hicieron su aparición en la arena política paraguaya. En el caso del reclamo de tierra de la comunidad de Xakmok Kásek, Villagra relata el trabajo de los chamanes sobre los senadores y autoridades del Poder Ejecutivo, para que ellas aceptaran entregar las tierras a la comunidad. A diferencia de lo que había pasado entre los maskoy en el reclamo de tierra de los años 80 -en donde el trabajo de los chamanes para ablandar el py'a ("estomago/corazón", en guaraní paraguayo) de los políticos se había dado paralelamente a la alianza política con la iglesia católica, sin que esas dos prácticas entraran abiertamente en diálogo (Bonifacio, 2013a) —, en el caso de Xakmok Kásek, se da la confianza necesaria para que los enxet y sanapaná puedan plantear abiertamente a la onc la incorporación de sus praxis políticas — que involucran la alianza de seres no-humanos - en el proceso de reivindicación de tierra, y para que la ONC incorpore esas prácticas como parte de ese proceso. A pesar de eso, Villagra relata honestamente su escepticismo en reconocer la efectividad de esas prácticas - justamente como el punto retrospectivo de "equivocación" recíproca acuñado por Viveiros de Castro, al que aludíamos más arriba—, admitiendo así la distancia creada por las diferencias ontológicas y su adherencia espontánea a una praxis política que no incluye la presencia de los espíritus auxiliares -y que, si llega a tanto, lo hace partiendo de la preponderancia de lo "político" por sobre otras prácticas socio-culturales no escindidas para los indígenas. En el caso de los maskoy, se pone en duda la coincidencia, a menudo planteada por las organizaciones internacionales, entre la existencia de una arena política entre los pueblos indígenas y la creación de organizaciones indígenas "modernas" oficialmente reconocidas. Mientras que las organizaciones indígenas constituyen la arena política de una forma "pensable" (thinkable) a través de las categorías científicas y políticas modernas, los rituales de iniciación femenina son "impensables" (De la Cadena, 2015) como eventos constitutivos de la misma. Presentando los rituales de iniciación como praxis política, se busca incorporar y reconocer explícitamente la presencia de seres no-humanos en la arena políti$c a, y$ la necesidad de la existencia de un espacio en donde la alianza con estos seres pueda ser actualizada y fortalecida. En el evento de los rituales, los maskoy existen como sujetos políticos en ensamblaje con los seres no-humanos (cosas y dueños de plantas, animales, ríos y otros seres) que los rodean.

Nuestra intención no es declarar la incompatibilidad entre diferentes conceptualizaciones de la arena política, sino que mostrar las conexiones (parciales) que las constituyen, y asumir que distintos ensamblajes puedan co-existir a través de una praxis cosmopolítita que los haga posibles y que haga posible el dialogo, más allá de la distinción entre naturaleza y cultura en la que algunas de ellas operan. 
Valentina Bonifacio es Marie-Curie Research Scholar en las universidades Ca' Foscari (Italia) y Parsons-The New School (usa), y consiguió su PhD in Social Anthropology with Visual Media en la Universidad de Manchester (uk). Es autora de artículos y documentales y ha trabajado en la cooperación al desarrollo antes de dedicarse al trabajo académico. Actualmente está curando una exhibición itinerante sobre la historia de Puerto Casado (Chaco Paraguayo).

Rodrigo Villagra Carron es abogado por la Universidad Nacional de Asunción (1996) y Magister (1998) y Doctor en Antropología Social por la Universidad de Saint Andrews (2009), Escocia. Actualmente es presidente de la organización "Tierraviva a los pueblos indígenas del Chaco", miembro del Centro de Estudios Antropológicos de la Universidad Católica de Asunción e investigador del PRONII-CONACYT-Paraguay.

\section{REFERÊNCIAS BIBLIOGRÁFICAS}

\section{ARENAS, Pastor}

1981 Etnobotánica Lengua-Maskoy. Buenos Aires, Fundación para la Ciencia, la Educación y la Cultura.

BLASER, Mario

2010 Storytelling Clobality: A Border Dialogue Ethnography of the Paraguayan Chaco. Durham, Duke University Press.

BONIFACIO, Valentina

2009 Casado's Legacy (documentary). Distributed by Granada Centre for Visual Anthropology, Manchester, UK.

2013a "Meeting the Cenerals: A Political Ontology Analysis of the Paraguayan Maskoy Stuggle for Land". Anthropologica, 55: 385-398.

2013b "Building up the Collective: A Critical Assessment of the Relationship between Indigenous Organizations and International Cooperation in the Paraguayan Chaco". Social Anthropology, 21(4). 
Dossı̂̂ | Valentina Bonifacio y Rodrigo Villagra Carron | Conexiones inestables,

BONIFACIO, Valentina y VILLAGRA, Rodrigo

2015 "Los maskoy de Puerto Casado y los angaité de Puerto Pinasco. Un recuento del tiempo del tanino". In: CÓRDOBA, Lorena; BOSSERT, Federico; y RICHARD, Nicolás (orgs.). Capitalismo en las selvas. Enclaves industriales en el Chaco y Amazonía Indígenas (1850-1950). San Pedro de Atacama, Ediciones del Desierto, pp. 233-270.

BROWN, Michel F.

1993 "Facing the State, Facing the World: Amazonia's Native Leaders and the New Politics of Identity". L'homme, vol. 33, n. 126: 307-326.

CHASE-SARDI, Miguel y SUSNIK, Branislava

1995 Los indios del Paraguay. Madrid, Mapfre s.A.

COMINGES, Juan de

1882 Exploraciones al Chaco del Norte. Buenos Aires, Alsina.

DE LA CADENA, Marisol

2010 "Indigenous Cosmopolitics in the Andes: Conceptual Reflections beyond 'Politics'. Cultural anthropology, 25(2).

2014 "Runa. Human but Not Only". Hau: Journal of ethnographic theory, 4(2).

2015 Earth Beings: Ecologies of Practice Across Andean Worlds. Duke University Press.

DELPORTE, Jose

1992 El Choco o el Baile de los Toba Maskoy. Tesis de peritaje: Universidad Técnica Particular de Loja.

KALISCH, Hannes

2012 "Lectura de las fiestas enlhet". In ESCOBAR, Ticio (org.). La belleza de los otros. Asunción, Servilibro.

KIDD, Stephen

1992 Religious Change: A Case-Study amongst the Enxet of the Paraguayan Chaco. Durham, dissertação, University of Durham.

1999 Love and Hate among the People without Things. The Social and Economic Relations of the Enxet People of Paraguay. St. Andrews, tese, University of St. Andrews. 
Dossı̂̂ | Valentina Bonifacio y Rodrigo Villagra Carron | Conexiones inestables,

LATOUR, Bruno

1990 "Postmodern? No, Simply Amodern! Steps towards an

Anthropology of Science". Stud. Hist. Phil. Sci., 21.

MALINOWSKI, Bronislaw

2005 Argonauts of the Western Pacific: An Account of Native

Enterprise and Adventure in the Archipelagoes of

Melanesian New Guinea. Londres, Routledge.

SANTOS-GRANERO, Fernando

1986 "Power, Ideology and the Ritual of Production in

Lowland South America". Man, 21(4): 657-679.

\section{VERIJDT, Gemma}

2013 The Rush for the Last South-American Land Reserve: the Paraguayan Chaco. An Analysis of New Investors in the Paraguayan Chaco and Their Economic, Social and Environmental Effects. Holanda, disssertação, University of Utrecht.

VILLAGRA, Rodrigo

2008 "Los liderazgos Enhlet-Enenhlet. Los cambios, las continuidades, las paradojas" In BRAUSTEIN, José y MEICHTRY (orgs.), Liderazgo, representatividad y control social en el Gran Chaco. Resistencia, Editorial Universitaria de la Universidad Nacional del Nordeste.

2009 The Two Shamans and the Owner of the Cattle: Alterity, Storytelling and Shamanism amongst the Angaité of the Paraguayan

Chaco. St. Andrews, tese, University of St Andrews.

VIVEIROS DE CASTRO, Eduardo

2015 The Relative Native: Essays on Indigenous Conceptual Worlds. Chicago, Hau books.

\section{SITIOS WEB}

Casos en etapa de supervisión de la Corte Interamericana de Derechos

Humanos (Corte IDH). Agosto 2016. Disponible en: http://www.corteidh.or.cr/cf/ jurisprudencia2/casos_en_etapa_de_supervision.cfm, recuperado el 31/08/2016.

"Este mes podría concretarse reivindicación territorial de más de 20 años de antigüedad. Cerardo Larrosa, dirigente de la comunidad indígena Xákmok kásek", Julio 2016. Disponible en: http://www. tierraviva.org.py/?page_id=2128, recuperado el 28/09/2016. 


\section{Unstable, Unforseen and Lost Connections: Expanding the Political Arena in Development Cooperation and In- digenous Communities in the Paraguayan Chaco}

\section{ABSTRACT}

The article is a reflection on the definition of the political arena in the Paraguayan context and beyond. In particular, it provides a close look on the way in which this arena gets stretched and blurred in the space of encounter between indigenous communities and development institutions in two specific case studies. The first is the case of the maskoy communities of Alto Paraguay, where the absence of "developmental" forms of indigenous organizations parallels a strong re-enactment of collective ceremonies that are not considered political by non-indigenous observers but they certainly are if we try to reformulate "the political" according to other ontological premises. In the second case, the Sanapaná and Enxet community of Xakmok Kásek works with an advocacy Nco to reclaim a part of their ancestral land before the Paraguayan Parliament through an expropriation law project against the landowner who holds the land title. At reaching point of discussion of the law project, the community ask the NCO an additional support to hold a shamans' meeting to act upon the lawmakers. The example show once more that politics that not reduces its realm to the actions of humans alone. Both cases also altogether demonstrate the feeble developmental attempts to separate "human" from "nature" and the limitations of advocacy Nco endeavours to fully understand politics as cosmopraxis. Thus, the indigenous challenges to the "modern" limits of the political arena, which provokes tensions and misunderstandings, ask to slow down reasoning and re-imagine a configuration for future alliances and political practices.

\section{KEYWORDS}

Political Arena,

Development, Indigenous Peoples of Chaco, Shamanism, Cosmopraxis.

Recebido em novembro de 2015. Aceito em setembro de 2016. 